TITLE:

\title{
New Aspects in the Coordination Chemistry of Ge- and Sn- Containing Metallaaromatic Compounds
}

\section{$\operatorname{AUTHOR}(\mathrm{S})$ :}

Tokitoh, Norihiro; Inamura, Koji; Mizuhata, Yoshiyuki

\section{CITATION:}

Tokitoh, Norihiro ...[et al]. New Aspects in the Coordination Chemistry of Ge- and SnContaining Metallaaromatic Compounds. Phosphorus, Sulfur, and Silicon and the Related Elements 2011, $186(6)$ : 1323-1325

\section{ISSUE DATE:}

2011-06

URL:

http://hdl.handle.net/2433/156921

\section{RIGHT:}

(C) 2011 Taylor \& Francis Group, LLC; この論文は出版社版でありません 。引用の際には出版社版をご確認ご利用ください。; This is not the published version. Please cite only the published version. 
New Aspects in the Coordination Chemistry of Ge- and Sn-Containing Metallaaromatic

\title{
Compounds
}

\author{
Norihiro Tokitoh,* Koji Inamura, and Yoshiyuki Mizuhata \\ Institute for Chemical Research, Kyoto University, Gokasho, Uji, Kyoto 611-0011, Japan, \\ tokitoh@boc.kuicr.kyoto-u.ac.jp \\ Running Head: Coordination Chemistry of Metallaaromatic Compounds
}

Abstract: Ge- and Sn-containing $\eta^{6}$-Metallaarene- $\mathrm{Cr}(\mathrm{CO})_{3}$ complexes showed unique reactivity leading to the formation of unexpected products. The formation mechanism of the new complexes was discussed together with their molecular structures.

Keywords: metallaaromatic compound, chromium, coordination chemistry

Introduction: We have already succeeded in the synthesis and isolation of various stable metallaaromatic compounds containing a heavier group 14 element (heavy aromatics) by taking advantage of kientic stabilization afforded by an efficient steric protection group, Tbt [1]. As an extension of this chemistry, we have examined the complexation of sila- and germabenzenes and 2-stannanaphthalene by the ligand exchange reactions with 
$\left[\mathrm{M}\left(\mathrm{CH}_{3} \mathrm{CN}\right)_{3}(\mathrm{CO})_{3}\right](\mathrm{M}=\mathrm{Cr}, \mathrm{Mo}, \mathrm{W})$ and succeeded in the isolation of the corresponding $\eta^{6}-$ metallaarene complexes 1-3 [2]. Here, we present the synthesis of novel $\eta^{6}$-metallaarene$\mathrm{Cr}(\mathrm{CO})_{3}$ complexes containing a $\mathrm{Si}$ or Ge atom in the metallaaromatic ring (4-6) together with the unique reactivity of 3-6 leading to the formation of unexpected products.<smiles>O=C[Ge](O)(C=O)c1ccccc1</smiles>

1: $\mathrm{E}=\mathrm{Si}$

2: $\mathrm{E}=\mathrm{Ge}$

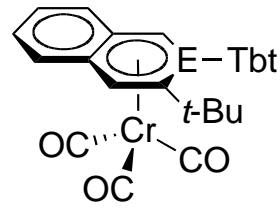

3: $E=S n$

4: $\mathrm{E}=\mathrm{Ge}$

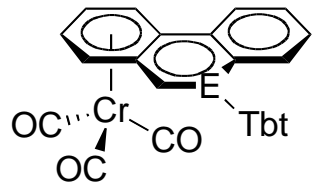

5: $\mathrm{E}=\mathrm{Si}$

6: $E=G e$

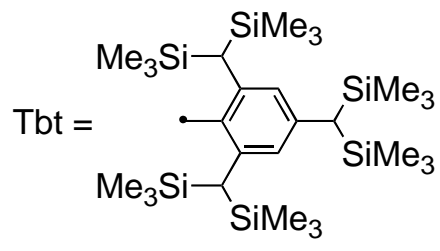

Results and Discussion: Ligand exchange reactions of isolated 2-germanaphthalene 7 and 9metallaphenantherenes $\mathbf{8}$ and $\mathbf{9}$ were performed according to the procedures similar to those previously reported for the complexes 1-3 (Scheme 1).

\section{Scheme 1.}

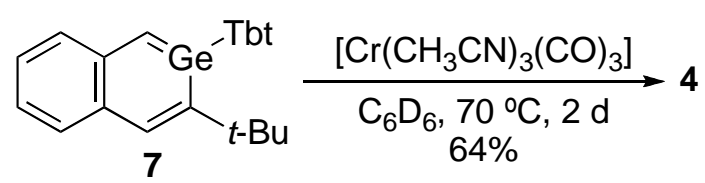

Tbt

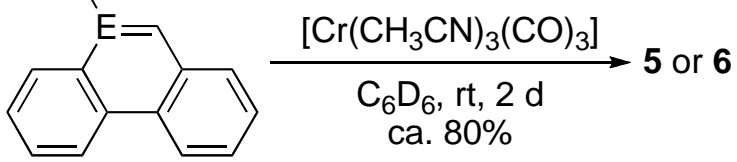

8: $\mathrm{E}=\mathrm{Si}$

9: $\mathrm{E}=\mathrm{Ge}$

In the case of 7, the coordination of $\mathrm{Cr}(\mathrm{CO})_{3}$ moiety occurred at the $\mathrm{GeC}_{5}$ ring similarly to 2stannanaphthalene $\mathbf{3}$. In the cases of $\mathbf{8}$ and $\mathbf{9}$, on the other hand, $\mathrm{Cr}(\mathrm{CO})_{3}$ moiety coordinated to the $\mathrm{C}_{6}$-ring far from $\mathrm{Tbt}$ group instead of to the $\mathrm{EC}_{5}$ rings, complexes $\mathbf{5}$ and $\mathbf{6}$ keep isolated metallene $(\mathrm{Si}=\mathrm{C}, \mathrm{Ge}=\mathrm{C})$ moieties. The ${ }^{1} \mathrm{H}$ NMR signals of 10 -position were observed at 6.33 (5) and 7.17 (6) ppm, which values are dramatically high-field shifted from those of $\mathbf{8}$ and 9 
(8: $7.27 ; 9: 8.13 \mathrm{ppm})$. These results indicated the increase of double-bond character of metallene moieties and the decrease of $\pi$-electron delocalization on the central $\mathrm{EC}_{5}$ rings.

Although complex 4 has high thermal stability, heating of tin-analogue 3 at $70{ }^{\circ} \mathrm{C}$ afforded unusual stannylene complex $\mathbf{1 0}$ quantitatively, in which Tbt group migrated to the neighboring carbon of the tin atom and the $\mathrm{Cr}(\mathrm{CO})_{3}$ moiety moved to the $\mathrm{C}_{6}$-ring (Scheme 2).

\section{Scheme 2.}
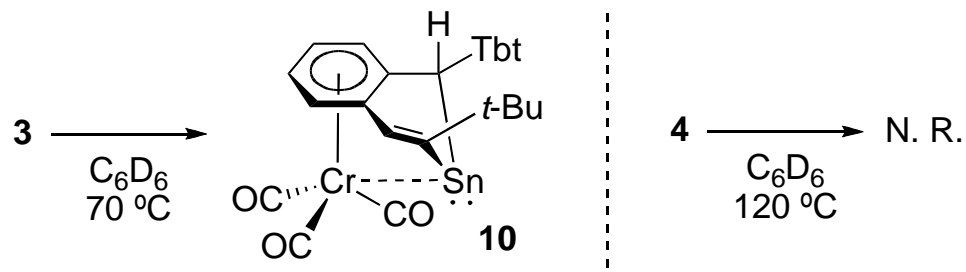

This reactivity is characteristic of the stannanapahthalene- $\mathrm{Cr}(\mathrm{CO})_{3}$ complex, and the free 2stannanaphthalene is stable under the same conditions. In the ${ }^{119} \mathrm{Sn}$ NMR of $\mathbf{1 0}$, the signal appeared at $-573 \mathrm{ppm}$, which is an unusual value as that of a stannylene (typically around ca. $+2000 \mathrm{ppm}$ ), indicating some interaction between the $\mathrm{Sn}$ and $\mathrm{Cr}$ atoms. Actually, the X-ray crystallographic analysis of $\mathbf{1 0}$ revealed the close Sn...Cr distance [3.1214(8) $\AA$ ], which is much shorter than the sum of van der Waals radii of Sn and $\mathrm{Cr}$ atoms $(4.17 \AA)$.

Complexes 5 and $\mathbf{6}$ were thermally stable at room temperature in the solid state. However, heating of the benzene solution of 5 or 6 at $80{ }^{\circ} \mathrm{C}$ resulted in the ligand exchange to afford the mixture of free 8 or 9 and $\left[\left(\eta^{6}\right.\right.$-benzene $\left.) \mathrm{Cr}(\mathrm{CO})_{3}\right]$ (Scheme 3). Unexpectedly, on standing at room temperature, these mixtures were found to give the corresponding new complexes slowly. This reaction was assisted by photo-irradiation and completed after 13 hours (Scheme 
2). Judging from the results of the ${ }^{1} \mathrm{H}$ and ${ }^{13} \mathrm{C}$ NMR spectroscopy, the structures of the products were initially assigned as $\pi$-complexes $\mathbf{1 1}$, which might be generated by the leaving of one $\mathrm{CO}$ ligand by photo-irradiation and the coordination of the metallene moiety to the vacant coordination site of the chromium center. However, X-ray crystallographic analyses of the products clearly showed the evident interaction between the Si or Ge atom and the carbon atom of $\mathrm{CO}$, which may be rationalized with the novel four-membered metallacycles postulated as 12. The distances of $\mathrm{E}-\mathrm{C}^{2}$ were found to be $2.374 / 2.286(\mathrm{Si})$ and $2.475 / 2.498$ (Ge) $\AA$, respectively, which are longer than the ypical lengths of $\mathrm{E}-\mathrm{C}$ single bonds $[1.88$ (Si) and $1.95(\mathrm{Ge}) \AA]$ and much shorter than the sums of the van der Waals radii $[3.80(\mathrm{Si}+\mathrm{C})$ and $3.70(\mathrm{Ge}+\mathrm{C}) \AA]$. These significant interactions were supported by the two distinguishable signals of $\mathrm{CO}$ in their ${ }^{13} \mathrm{C}$ NMR spectra.

\section{Scheme 3.}

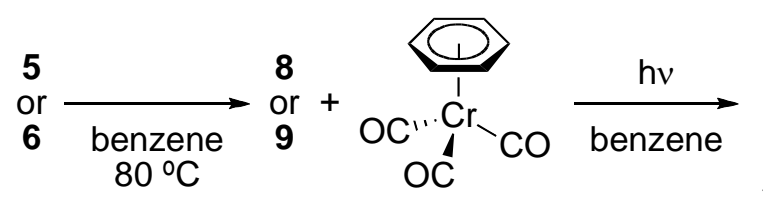

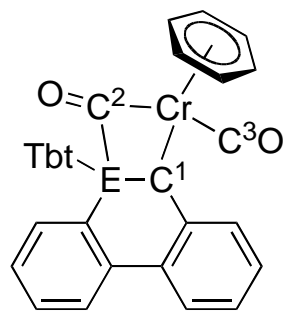

12

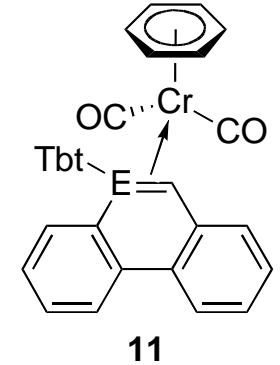

11

Conclusions: We have succeeded in the synthesis of novel types of $\mathrm{Cr}(\mathrm{CO})_{3}$ complexes of metallaaromatic compounds 4-6. Of particular notes among the unique reactivity of the new complexes are the thermolysis of $\mathbf{3}$ and the photolysis of $\mathbf{5}$ and $\mathbf{6}$ leading to the formation of 
unprecedented types of complex 10 and 12. Detailed investigation of the structures of newly obtained complexes from experimental and theoretical aspects and further elucidation of the reactivity of complexes 3-6 will be reported elsewhere.

\section{References:}

[1] For a review, see: Tokitoh, N. Acc. Chem. Res. 2004, 37, 86.

[2] a) Shinohara, A.; Takeda, N.; Sasamori, T.; Matsumoto, T.; Tokitoh, N. Organometallics 2005, 24, 6141. b) Nakata, N.; Takeda, N.; Tokitoh, N. Angew. Chem. Int. Ed. 2003, 42, 115.

c) Mizuhata, Y.; Sasamori, T.; Takeda, N.; Tokitoh, N. J. Am. Chem. Soc. 2006, 128, 1050. d)

Mizuhata, Y.; Sasamori, T.; Nagahora, N.; Watanabe, Y.; Furukawa, Y.; Tokitoh, N. Dalton Trans. 2008, 4409. 